\title{
A multi-product, multi-period model to select supplier for deteriorating products while considering uncertainty as well as backorder
}

\author{
Mohsen Lashgari ${ }^{1} \cdot$ Seyed Jafar Sadjadi ${ }^{1} \cdot$ Misugh Sahihi $^{1}$
}

Received: 1 November 2017 / Accepted: 19 March 2018/Published online: 25 June 2018

(c) The Author(s) 2018

\begin{abstract}
Determining supplier and optimum order of the quantity is an issue of great importance in logistics management for many companies. In this regard, it is crucial to determine the best decisions for the order quantity as well as the most suitable supplier through considering existing limitations and uncertainties. To optimize a multi-product, multi-period model with select supplier for deteriorating products, while uncertainty of future economic conditions directly affects the problem conditions. In this regard, a mixed integer definite programing model is introduced, and afterwards, the proper robust structure is established through a two-phase scenario-based approach. The behavior of the main features of the inventory system elaborated upon in this article, that is, multi-product, uni-level, multi-period inventory system, has been modeled under the influence of uncertain economic environment. In the final phase pattern, search method is employed to determine proper answers, the results of which are analyzed, to shed light on various aspects of the solving procedure, as well as the problem itself. The applicability of the proposed model is shown by an illustrative example.
\end{abstract}

Keywords Deteriorating items · Inventory control $\cdot$ Robust optimization $\cdot$ Pattern search $\cdot$ Scenario based

\section{Introduction and literature review}

Considering the fact that trustworthy suppliers enable manufacturers to lower the inventory costs of the product while enhancing the quality, an erroneous opt of the supplier may predispose financial as well as technical resources, through a supply chain. Thus, the magnitude of the supplier selection process, from manufacturer perspective, and the growing fretfulness of selectors towards this matter, can be easily perceived. On the other hand, the resplendence of philosophy of JIT production attracting producers' predilection towards it makes the supplier

Mohsen Lashgari

mohsen.lashgari2010@gmail.com

Seyed Jafar Sadjadi

sjsadjadi@iust.ac.ir

Misugh Sahihi

misugh.sahihi@gmail.com

1 School of Industrial Engineering, Iran University of Science and Technology, Tehran, Iran selection a strategic issue, and in such condition, it becomes vital to establish a long-term relation with optimum number of suppliers, guaranteeing a profitable collaboration. Furthermore, this opportunity paves the way for enhancing manufacturing operations.

Supplier selection, as well as determining the optimum order quantity are the two most important issues, directly affecting production and logistics managerial decisions. On the occasion in which suppliers are picked out appropriately, higher quality and long lasting associations are much more achievable. The circumstances and strategies through which a manufacturer creates connection with environment and he or she interacts with other companies cause influence on one another. In addition, while a mistake in selecting supplier may turn apart the financial and operational situation of a profitable company, a proper choice regarding suppliers and the optimum order quantity is capable of setting the stepping stones of enhanced competitiveness in the market and customer satisfaction through mitigating the buying costs. Furthermore, determining the applicable optimum order quantity in 
production planning plays a crucial role regarding the strategic concerns.

Many approaches are taken into account to develop a proper model that best suits the real-world inventory problems. In this regard, fuzzy approaches have been greatly studied. Bevilacqua and Petroni (2002) introduced an algorithm for selecting the supplier through eight steps, based on a fuzzy QFD technic. Saaty (2004) applied a fuzzy analytical hierarchy process for this purpose. In this regard, he developed a model to acquire criteria required for defining the supplier selection problem from the industry experts. He decomposed the supplier section problem through a controlled hierarchy, thus he could point out the specified priorities. In this regard, criteria are divided into four categories, that is, profit, opportunities, costs, and risks. Each of these criteria is also divided into subsequent subcategories. Kumar et al. (2004) considered a fuzzy mixed integer programing framework as their solving method. Their model incorporated three objectives of minimizing net cost, minimizing number of returned items and, last but not least, minimizing delays. The objective function of their model was subject to the constraints of supplier capacity and thorough satisfaction of customer demands. The flexibility in share allocated to suppliers, total budget and each supplier's budget was also modeled and discussed, while some of the parameters were demonstrated through fuzzy concept. Rabbani (2011) and Taleizadeh et al. (2015) presented a novel method based on fuzzy expert system, capable of estimating fuzzy parameters for determining multi-level multi-product cumulative size subject to limited capacity. He implemented alpha-cut method for the fuzzy mathematic programing to transform it to a classic model, the parameters of which are considered to be uncertain. In the next step, the proposed model was put to use in a household appliance manufacturing company and the outcomes were analyzed.

Through the literature, the characteristics of inventory systems with different structures are analyzed and discussed. Lashgari et al. dealt with an inventory management problem in which two levels of credit periods where considered, according to the size of the order quantity, while the time horizon of the problem is finite. Shortage was permitted and completely backordered in their study, for which they proposed a solving approach. Xia and $\mathrm{Wu}$ (2007) integrated existence of variegated criteria effecting supplier constraints as well as analytical hierarchy analysis of data exalted via theory of uneven sets, through mixed integer programing. They made a presumption that the purchased goods are the basis for quantity or miscellany. The model is further discussed through a couple of numerical examples. In addition, different types of deteriorations are introduced in the literature. Taleizadeh has studied inventory management of gasoline as an evaporating product, while flexible payment approaches are available for customers. In a research, Lee et al. (2013) developed an assimilated model, intended to program the order quantity, parallel with supplier selection while considering quantity discount. They designed a mix integer programming model, the target of which is to minimize costs of transportation, maintenance, purchase, and ordering. They applied Genetic meta-heuristic algorithm to reveal the answer. In addition, this study is executed in advanced technologies company in Taiwan.

From the solving point of view, various approaches and methods are discussed through the literature. The article published by Senyigit and Soylemez (2012) enjoyed heuristic analysis in their model to structure a programing framework for calculating order quantity and decide the proper suppliers. They devised a multi-level multi-product mixed linear integer programing model, aimed to minimize existing costs through determining the optimum quantity and they simulated the model with ARENA 4.0. Rezaei and Davoodi (2011) expanded multi-objective non-linear mixed integer model to a multi-period multi-product multisupplier structure, aimed to minimize costs while maximizing quality level as well as service level. The genetic meta-heuristic algorithm is introduced as the proposed solving approach and the results from two scenarios, that is, sanctioned shortage and unsanctioned shortage are discussed. In addition, Taleizadeh et al. (2009, 2010a, b, 2011, 2013a, b) and Taleizadeh and Nematollahi (2014) have published the articles in which they developed multi-product models in different situations and have implemented met heuristic algorithms to solve the models. Furthermore, Taleizadeh et al. (2015) and Rabbani (2011) undertook a study of a two-echelon vendor managed inventory model of a vendor and several retailers who do not compete with each other. They considered the vendor as the leader and the retailers as the followers, through a Stackelberg approach and developed a solving algorithm based on proving the concavity of the profit function.

The issues incorporated in inventory models also cover a significantly wide range of parameters. In their study, Ebrahim et al. (2009) developed a model incorporating numerous types of discounts. They further took limitations such as suppliers' capacity and demand, to name but two, into account. Scatter search meta-heuristic algorithm was implemented to discover an apposite answer for the model and its characteristics are discussed for assorted types of discounts.

Earlier to discuss the literature of study, an overall glimpse to the subject of deteriorating items is felt to be desirable. Bakker et al. (2012) reviewed the literature of subjects that are considered for deteriorating products since 2001, such as discount, back order and lost sale shortages, uni-product and/or multi-product and differed payments. Li 
et al. (2010) also applied a comprehensive review on inventory control of the deteriorating items. Khanlarzade et al. (2014) undertook an extensive study of literature on inventory control models through a supply chain, developed for deteriorating products from 1963 to 2013. Articles published by Lashgari et al. (2016), Diabat et al. (2017) Taleizadeh and Nematollahi (2014), Taleizadeh et al. (2013b, c), Taleizadeh (2014) have elaborated upon the deterioration behavior of the products in inventory models. Skouri and Papachristos (2002) and Zhang et al. (2015) represented an inventory control model, including costs of ordering, maintenance, deterioration, shortage, and opportunity. In this model, ordering cost is dependent to order quantity, deterioration takes place constantly and independent from time, and shortage is permitted. In addition, they presented an inventory model for a product, demand of which is a two-factor function of time. In this model, the assumption of deterioration is modeled through a Wibol probability function of time, and the shortages are accepted as backorder. Zhang et al. considered consumer demand varies according to the sales price and quantities of the products available in the store. They modeled the replenishment cycle for non-instantaneous deteriorating items and employed Pontryagin's maximum principle to determine the optimum dynamic pricing strategy.

The inventory model was improved by Hung (2011). He replaced the demand and Wibol probability distribution of deterioration behavior with general functions for demand and deterioration. He remodeled the problem and calculated the exact answer. Valliathal and Uthayakumar (2009) studied a discrete inventory control model for deteriorating items under the authorized back order shortage while considering an exponential conduct for deteriorating items. Sarkar et al. (2012) developed an inventory control model with limited time horizon for a product with a deteriorating function of time. In this study, besides allowing back order shortage, demand is an exponential function of time. The effects of reference prices on a deteriorating inventory system were studied by Mulvey et al. (1995). They modeled the investment decision on preservation technology as well as pricing of deteriorating products through an inventory model and in which demand is affected by time, price and reference price effects.

Reviewing the articles published in the literature of inventory control, supplier selection, deteriorating products, and uncertainty proves the fact that the literature pertinent to these areas is short of a comprehensive study developing a holistic model, that is capable of taking all the relevant yet practical concepts into account. It is deeply felt that a comprehensive investigation is needed to bring various and even contradicting relative points of view into practice, through a practical framework. To fulfil this gap, a multi-product, multi-period model is represented in this article, the aim of which is to select supplier for deteriorating products while considering uncertainty as well as backorder.

In the present study, the common inventory costs, as well as novel issues including maximum capacity for transportation vehicle and limitation on the order quantity accompanied by a transportation cost are considered. Furthermore, the value of the products that are subjects of the present study is modeled from a deteriorating behavioral point of view. Thus, the value of the inventory decreases as the time passes by. Last but not least, backorders are allowed in our problem and they are partially satisfied. This assumption is practical for real-world problems which can be easily concluded from the growing use of partial backorder models, progressively enriching the inventory literature.

\section{Problem definition}

Consider a business offering a range of products that are provided from various suppliers. In this situation, the fact that the costs related to the suppliers usually vary due to their capabilities increases the complexity of selecting the optimum choice to buy the supplies from. The optimum choice includes a supplier who is capable of providing the requested order, and more importantly, offers the best price. These characteristics are outcomes of the fact that the first objective of every business is to keep their costs in the lowest level possible, and an important way to do so, is to lower supply costs.

The process of selecting the best supplier must be conducted in a manner that inventory costs, which is the accumulation of ordering cost, transportation cost, maintenance cost, and shortage cost of every unit of the product is minimized. Although, due to the nature of these costs, minimizing all of them ends up in pursuing controversial goals. Other obstacles are also influencing the problem, the most important of which are the limitations of the problem. These limitations are discussed thoroughly in subsequent sections.

\section{Model}

To solve the discussed problem, we developed a multiproduct, multi-constraint framework for selecting the supplier for deteriorating items. The parameters and variables of the model are as follows:

Parameters:

\section{Indexes}

$i$ Product index.

$j$ Supplier index.

$t$ Period index. 


\section{Parameters}

$D_{i t} \quad$ Demand of product $i$ in period $t$.

$A_{i j t} \quad$ Order cost of product $i$ from supplier $j$ in period $t$.

$C_{i j t} \quad$ Cost of buying product $i$ from supplier $\mathrm{j}$ in period $t$.

$h_{i t} \quad$ Maintenance cost of product $i$ in period $t$.

$\pi_{i} \quad$ Time dependent shortage cost of product $i$.

$S_{j} \quad$ Transportation cost from supplier $j$.

$b_{j} \quad$ Maximum transportation capacity of supplier $\mathrm{j}$ to retailer.

$\mathrm{MC}_{t} \quad$ Maximum available budget in period $t$.

$\mathrm{MS}_{t} \quad$ Maximum available space in period $t$.

$W_{i} \quad$ Required space for product $i$.

$\theta_{i} \quad$ Deteriorating rate of product $i$.

$T_{i} \quad$ Length of time interval between two successive orders of item $i$.

\section{Decision variables}

$F_{i j t} \quad$ Binary variable which is equal to 1 , if product $i$ is ordered from supplier $j$ in time interval $t$. Else, equals to zero (first phase's decision variable).

$Q_{i j t} \quad$ Order quantity of product $i$ to supplier $j$ at time interval $j$ (second phase's decision variable).

$K_{i t} \quad$ Time interval, in which, shortage takes place for item $i$ in period $t$ (second phase's decision variable).

\section{The proposed model}

The model developed to solve the problem is as follows. The objective function is discussed hereunder:

$$
\begin{aligned}
\operatorname{Min} \Psi & =\sum_{t} \sum_{i}^{m} \sum_{j}^{n} A_{i j} F_{i j t}+\sum_{t} \sum_{i}^{m} \sum_{j}^{n} C_{i j t} Q_{i j t} \\
& +\sum_{t} \sum_{i}^{m} h_{i t} \frac{D_{i t} K_{i t}^{2} T_{i t}}{2}+\sum_{t} \sum_{i}^{m} \pi_{i t} \frac{\beta_{i} D_{i t}\left(1-K_{i t}\right) T_{i t}}{2} \\
& +\sum_{t} \sum_{i}^{m} \sum_{j}^{n} S_{i j}\left[\frac{Q_{i j t}}{b_{i}}\right]
\end{aligned}
$$

$$
\text { S.t. } Q_{i t}=\left(\frac{D_{i t}}{\theta_{i}}\left(e^{\theta_{i} K_{i t} T_{i t}}-1\right)+\beta_{i} D_{i t}\left(1-K_{i t}\right) T_{i t}\right) \quad \forall i, t
$$

$\sum_{j=1}^{m} Q_{i j t}=Q_{i t} \quad \forall i, t$

$Q_{i j t}<M * F_{i j t} \quad \forall i, j, t$

$\sum_{i}^{m} \sum_{j}^{n} C_{i j t} Q_{i j t} \leq \mathrm{MC}_{t} \quad \forall t$

$\sum_{i}^{m} \sum_{j}^{n} Q_{i j t} W_{i} \leq \mathrm{MS}_{t} \quad \forall t$ $\sum_{j}^{n} F_{i j t} \geq 1 \quad \forall i, t$

$F_{i j t}$ is 0 or 1 ; and $Q_{i j t}, k_{i t} \geq 0 \quad \forall i, j, t$.

The first equation represents the objective function of the problem, intended to minimize the costs. The total cost, modeled as the objective function of the problem is composed of inventory costs, i.e., ordering, purchase, maintenance, shortage, and last but not least, transportation costs. The second equation determines the order quantity of the $i$ th item from the $j$ th supplier. The third equation guarantees that the total quantity ordered to the suppliers is equal to the total required amount. The fourth equation makes sure that the order quantity is zero when no purchase order is sent to the suppliers. Fifth equation assesses that the cost of the purchase from suppliers, regarding the considered budget to avoid any budget constraint violation sixth equation takes the space constraint into account regarding the limitations on available storage space. The last equations ensure that each product must be ordered to the supplier or suppliers, in each time period.

\section{Robust optimization of the proposed model}

According to discrete and scenario-related nature of our data, the robust optimization model, developed by Mulvey et al. (1995), is considered as reference model for this article. Accordingly, the robust optimization strategy, which is introduced for the first time by Mulvey et al. (1995), is discussed in this section. In addition, studies taken place for linearization of the proposed approach are also argued to construct the basis for the optimization model. In the last step, the scenario-based robust optimization model is provided and aspects of the model are presented.

Mulvey et al. (1995) employed scenario-based robust optimization model, combined with discrete goal programing in their research. It was a combination of controversial objectives while considering feasibility and proximity to optimum solution. The researchers integrated the two concepts of model robustness as well as solution robustness in their study. The core concept of this approach is that the programing of optimum solving method is through a robust framework, if for capturing each specific realization of the scenario, answer yet lingers in proximity of optimum solution. On the other hand, a model is claimed to be robust if the solving approach remains robust when for each specific realization of scenario, the final answer ends up somewhere close to optimum outcome. Unfeasibility of the model is measured by a penalty function. Optimum proximity stands for closeness optimality, while the phrase "nearly feasible" means that a low quantity is allocated to the relative penalty function. 
Mulvey et al. (1995) represent the robust optimization model by considering a cost/benefit analysis between solution robustness and model robustness. In the model presented by them, there exist two types of variables: control variables and design variables. For the first set of variables, decision is made before realizing probabilistic parameters, which, by the time their realization has taken place, alteration of their quantities would not be possible. Control variables are adjusted after uncertainty parameters are realized. General form of Random programing with control and design variables is as follows:

Min $\Theta=\alpha^{T} x+\beta^{T} y$

S.t. $\varphi x=\lambda$

$\mu x+\gamma y=\varepsilon$

$x \geq 0, \quad y \geq 0$.

In this model, $x$ is vector of design variables and $y$ is vector of control variables. The parameters $\varphi$ and $\gamma$ in the model are both discrete and specified, while the second constraint is the design constraint. Parameters $\mu$, and $\varepsilon$ are uncertainty parameters, while third constraint is the control constraint. A specific realization of parameter, accompanied by uncertainty, is called a "scenario". Each scenario is shown by $S$ and the probability of this scenario is declared by $p_{s}$. A set of scenarios is represented by $\Omega$. Based on introduced symbols, the robust model of Mulvey et al. (1995) is as follows:

Min $\Theta=\theta\left(x, y_{1}, y_{2}, \ldots, y_{s}\right)+\tau \rho\left(\eta_{1}, \eta_{2}, \ldots, \eta_{s}\right)$

S.t. $\varphi x=\lambda$

$\mu_{S} x+\gamma_{S} y_{S}+\eta_{S}=\varepsilon_{S}$

$x \geq 0, y_{S} \geq 0, \eta_{S} \geq 0, \forall s \in \Omega$.

Uncertainty coefficients $\mu_{S}, \gamma_{S}$ and $\varepsilon_{S}$ are assigned to each scenario. Likewise, the control variable $Y$ can be allocated as $y_{s}$ to the scenario $S$, regarding that it is adjusted after scenario realization. Since the parameters of the model are uncertain, the outcome of the model may be infeasible for some scenarios. In this condition, $\eta_{S}$ represents the infeasibility of the model for each scenario $S$. Accordingly, for the scenarios in which model is feasible, $\eta_{S}$ equals to zero while acquires a positive quantity from the subsequent equations otherwise.

According to the model, objective function is composed of two sections. The former segment, that is, $\theta\left(x, y_{1}\right.$, $\left.y_{2}, \ldots, y_{s}\right)$, depicts the robustness of solving approach, while the latter, i.e., $\rho\left(\eta_{1}, \eta_{2}, \ldots, \eta_{s}\right)$, stands for model robustness and consists of error vectors, investigating the feasibility of control limitations under scenario $S$. The importance ratio of optimality robustness as well as feasibility robustness is formulated by the factor $\tau$.

Objective function is generally composed of design variables as well as control variables in the form of $\Theta=$ $f(x, y)$. Thus, the objective function for each scenario $S$ is $\Theta_{S}=f\left(x, y_{S}\right)$. High quantity for the variance illustrates the fact that a small variation in parameters with uncertainty may end up in substantial alteration in value of measuring function.

Mulvey et al. (1995) employed the following expression for depicting the robustness of their solution approach, in which $\sum_{s \in \Omega} p_{S} \Theta_{S}$ is the expected value of $\Theta_{S}$ for every scenario and $\delta$ is the allocated weight for variance of the solution, all of which are replaced with $\theta\left(x, y_{1}, y_{2}, \ldots, y_{s}\right)$ :

$$
\begin{aligned}
\theta\left(x, y_{1}, y_{2}, \ldots, y_{s}\right)= & \sum_{s \in \Omega} p_{S} \Theta_{S} \\
& +\delta \sum_{s \in \Omega} p_{S}\left(\Theta_{S}-\sum_{s^{\prime} \in \Omega} p_{s^{\prime}} \Theta_{s^{\prime}}\right)^{2} .
\end{aligned}
$$

To decrease the calculation steps, Yu and Li (2000) used an absolute deviation phrase instead of the second order:

$$
\begin{aligned}
& \sum_{s \in \Omega} p_{S}\left(\Theta_{S}-\sum_{s^{\prime} \in \Omega} p_{s^{\prime}} \Theta_{s^{\prime}}\right)^{2} \\
& \quad \theta\left(x, y_{1}, y_{2}, \ldots, y_{s}\right)=\sum_{s \in \Omega} p_{S} \Theta_{S}+\delta \sum_{s \in \Omega} p_{S}\left|\Theta_{S}-\sum_{s^{\prime} \in \Omega} p_{s^{\prime}} \Theta_{s^{\prime}}\right| .
\end{aligned}
$$

Even though the model includes absolute quantities, the linearization of the model is achievable through utilization of two extra variables Wagner (1975). Another straightforward method for simplification of the model, through adding merely one variable is represented by $\mathrm{Yu}$ and $\mathrm{Li}$ (2000) and Taleizadeh et al. (2009):

$$
\begin{aligned}
\operatorname{Min} \Theta= & \sum_{s \in \Omega} p_{S} \Theta_{S} \\
& +\delta \sum_{s \in \Omega} p_{S}\left[\left(\Theta_{S}-\sum_{s^{\prime} \in \Omega} p_{s^{\prime}} \Theta_{s^{\prime}}\right)+2 \omega_{s}\right]
\end{aligned}
$$

S.t. $\Theta_{S}-\sum_{s \in \Omega} p_{s} \Theta_{s}+\omega_{s} \geq 0$

$\omega_{s} \geq 0$.

As mentioned before, $\tau \rho\left(\eta_{1}, \eta_{2}, \ldots, \eta_{s}\right)$ is employed for unfeasibility of the model and shows the robustness of the model. Taking all aspects of the model discussed above into account, the final robust optimization model is as follows:

$$
\begin{aligned}
\operatorname{Min} \Theta= & \sum_{s \in \Omega} p_{S} \Theta_{S} \\
& +\delta \sum_{s \in \Omega} p_{S}\left[\left(\Theta_{S}-\sum_{s^{\prime} \in \Omega} p_{s^{\prime}} \Theta_{s^{\prime}}\right)+2 \omega_{s}\right] \\
& +\tau \sum_{s \in \Omega} p_{S} \eta_{s}
\end{aligned}
$$


S.t. $\Theta_{S}-\sum_{s \in \Omega} p_{s} \Theta_{s}+\omega_{s} \geq 0$

$\omega_{s} \geq 0$.

After shedding light on relevant concepts of robust optimization based on Mulvay's model, implantation of these concepts on inventory model is pursued in this step. As formerly enlightened, the objective function of the inventory model, is constructed by five types of costs, comprising order, purchase, maintenance, shortage and transportation costs, and depicted hereunder:

Ordering cost $=\mathrm{OC}=\sum_{t} \sum_{i}^{m} \sum_{j}^{n} A_{i j} F_{i j t}$

Fig. 1 Flowchart of solution algorithm
Purchase cost $=\mathrm{PC}=\sum_{t} \sum_{i}^{m} \sum_{j}^{n} C_{i j t} Q_{i j t}$

Carrying cost $=\mathrm{CC}=\sum_{t} \sum_{i}^{m} h_{i t} \frac{D_{i t} K_{i t}^{2} T_{i t}}{2}$

Shortage cost $=\mathrm{SC}=\sum_{t} \sum_{i}^{m} \pi_{i t} \frac{\beta_{i} D_{i t}\left(1-K_{i t}\right) T_{i t}}{2}$

Transportation cost $=\mathrm{TC}=\sum_{t} \sum_{i}^{m} \sum_{j}^{n} S_{i j}\left[\frac{Q_{i j t}}{b_{i}}\right]$.

According to robust optimization approach, the final objective function of the model is

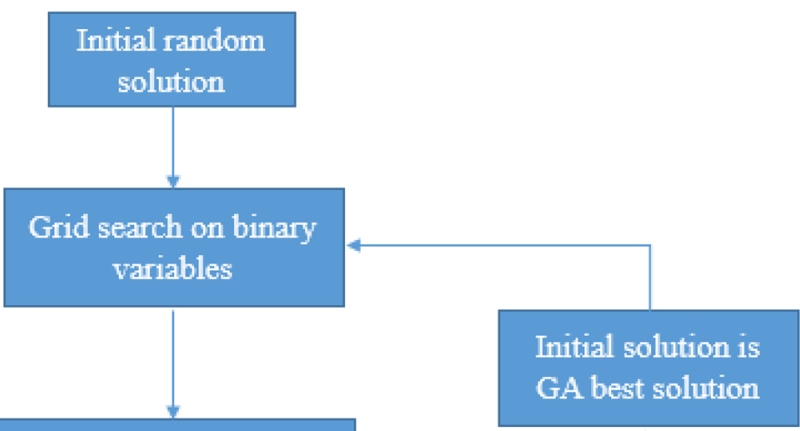

On each grid pattern

search is implemented

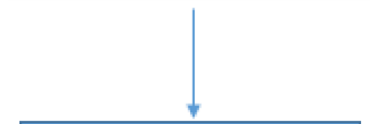

The best solution is

fed into GA

criteria is

satisfied 


$$
\begin{aligned}
\operatorname{Min} \Theta= & \sum_{s \in \Omega} p_{S}\left(\mathrm{OC}_{S}+\mathrm{PC}_{S}+\mathrm{CC}_{S}+\mathrm{SC}_{S}+\mathrm{TC}_{S}\right) \\
& +\delta \sum_{s \in \Omega} p_{S}\left[\left(\mathrm{OC}_{S}+\mathrm{PC}_{S}+\mathrm{CC}_{S}+\mathrm{SC}_{S}+\mathrm{TC}_{S}\right)\right. \\
& -\left(\sum_{s^{\prime} \in \Omega} p_{s^{\prime}} \mathrm{OC}_{s^{\prime}}+\mathrm{PC}_{s^{\prime}}+\mathrm{CC}_{s^{\prime}}+\mathrm{SC}_{s^{\prime}}+\mathrm{TC}_{s^{\prime}}\right) \\
& \left.+2 \omega_{s}\right]+\tau \sum_{s \in \Omega} p_{S} \eta_{s} .
\end{aligned}
$$

In addition, the constraints are formulated as

$$
\begin{gathered}
\text { S.t. } Q_{i t}=\left(\frac{D_{i t}}{\theta_{i}}\left(e^{\theta_{i} K_{i t} T_{i t}}-1\right)\right. \\
\sum_{j=1}^{m} Q_{i j t}=Q_{i t} \quad \forall i, t \\
Q_{i j t}<M * F_{i j t} \quad \forall i, j, t \quad \forall t \\
\sum_{i}^{m} \sum_{j}^{n} C_{i j t} Q_{i j t} \leq \mathrm{MC}_{t} \quad \forall t \\
\sum_{i}^{m} \sum_{j}^{n} Q_{i j t} W_{i} \leq \mathrm{MS}_{t} \quad \forall t \\
\sum_{j}^{n} F_{i j t} \geq 1 \quad \forall i, t .
\end{gathered}
$$

\section{Solving method}

Pattern search is a family of numerical optimization method that do not require gradient of the problem, to be optimized. Hence, PS can be used on functions that are neither continuous nor differentiable. The name pattern search was coined by. An early standard GA initially starts with a set of solutions, namely, a population of random chromosomes, which are evolved throughout successive iterations (generations) by genetic operators (selection,

\begin{tabular}{|c|c|c|c|}
\hline$i$ & & 2 & \\
\hline$j$ & & 3 & \\
\hline$t$ & & 2 & \\
\hline$s$ & & 3 & \\
\hline \multicolumn{4}{|l|}{$S_{1}$} \\
\hline$D_{11}=250$ & & $D_{21}=200$ & \\
\hline$D_{12}=200$ & & $D_{22}=300$ & \\
\hline \multicolumn{4}{|l|}{$S_{2}$} \\
\hline$D_{11}=350$ & & $D_{21}=150$ & \\
\hline$D_{12}=250$ & & $D_{22}=200$ & \\
\hline \multicolumn{4}{|l|}{$S_{3}$} \\
\hline$D_{11}=200$ & & $D_{21}=300$ & \\
\hline$D_{12}=165$ & & $D_{22}=380$ & \\
\hline$A_{111}=180$ & $A_{121}=200$ & & $A_{131}=300$ \\
\hline$A_{211}=300$ & $A_{221}=250$ & & $A_{231}=280$ \\
\hline$A_{112}=180$ & $A_{122}=200$ & & $A_{132}=300$ \\
\hline$A_{212}=300$ & $A_{222}=250$ & & $A_{232}=280$ \\
\hline \multicolumn{4}{|l|}{$S_{1}$} \\
\hline$C_{111}=6$ & $C_{121}=9$ & & $C_{131}=10$ \\
\hline$C_{211}=10$ & $C_{221}=7$ & & $C_{231}=12$ \\
\hline$C_{112}=6$ & $C_{122}=15$ & & $C_{132}=14$ \\
\hline$C_{212}=10$ & $C_{222}=11$ & & $C_{232}=5.5$ \\
\hline \multicolumn{4}{|l|}{$S_{2}$} \\
\hline$C_{111}=10$ & $C_{121}=6$ & & $C_{131}=11$ \\
\hline$C_{211}=11$ & $C_{221}=12$ & & $C_{231}=6.5$ \\
\hline$C_{112}=6$ & $C_{122}=15$ & & $C_{132}=13$ \\
\hline$C_{212}=12$ & $C_{222}=5$ & & $C_{232}=5.5$ \\
\hline \multicolumn{4}{|l|}{$S_{3}$} \\
\hline$C_{111}=10$ & $C_{121}=6$ & & $C_{131}=11$ \\
\hline$C_{211}=5$ & $C_{221}=10$ & & $C_{231}=12$ \\
\hline$C_{112}=13$ & $C_{122}=6$ & & $C_{132}=14$ \\
\hline$C_{212}=5.5$ & $C_{222}=11$ & & $C_{232}=14$ \\
\hline$h_{11}=3$ & & $h_{21}=2$ & \\
\hline$h_{12}=4$ & & $h_{22}=3$ & \\
\hline$\pi_{11}=6$ & & $\pi_{21}=5$ & \\
\hline$\pi_{12}=6$ & & $\pi_{22}=5$ & \\
\hline \multicolumn{4}{|l|}{$S_{1}$} \\
\hline$S_{11}=20$ & $S_{12}=30$ & & $S_{13}=25$ \\
\hline$S_{21}=35$ & $S_{22}=20$ & & $S_{23}=18$ \\
\hline$S_{2}$ & & & \\
\hline$S_{11}=20$ & $S_{12}=20$ & & $S_{13}=30$ \\
\hline$S_{21}=35$ & $S_{22}=20$ & & $S_{23}=18$ \\
\hline \multicolumn{4}{|l|}{$S_{3}$} \\
\hline$S_{11}=20$ & $S_{12}=35$ & & $S_{13}=30$ \\
\hline$S_{21}=35$ & $S_{22}=20$ & & $S_{23}=32$ \\
\hline$b_{1}=70$ & $b_{2}=40$ & & $b_{2}=60$ \\
\hline$\theta_{1}=0.1$ & & $\theta_{2}=0.15$ & \\
\hline$\beta_{1}=0.8$ & & $\beta_{2}=0.75$ & \\
\hline$M C_{1}=330$ & & $M C_{2}=300$ & \\
\hline$M S_{1}=35$ & & $M S_{2}=40$ & \\
\hline$W_{1}=0.55$ & & $W_{2}=0.6$ & \\
\hline$T_{1}=6$ & & $T_{2}=6$ & \\
\hline
\end{tabular}
crossover and mutation). The fitness value is assigned to each chromosome according to a problem-specific objective function. The new individuals (offspring) are produced based on current population (parents). In this paper, we develop a standard GA-based solution procedure to find good quality solutions for cardinality constrained portfolio problem (Fig. 1).
Table 1 Information of the numerical example 


\section{Numerical example}

In this section, a numerical example is solved, using the proposed robust model and the solving method that is introduced in previous sections, the results of which are discussed afterwards. In the present example, two products, three suppliers, two periods, and three scenarios are assumed for a hypothetical retailer. In addition, the uncertain parameters include, demand of product $i$ in period $t, D_{i j}$, purchase cost of product $i$ from supplier $j$ in period $t, C_{i j t}$, and transportation cost from supplier $j\left(S_{j}\right)$; thus, three dissimilar quantities are considered in three variegated scenarios. With this in mind, succeeding tables put forth the information of the numerical example (Table 1).

By equating the magnitude of variance, $\delta=0.5$, and violating constraints of budget and storage capacity, $\tau=0.5$, and solving the model employing pattern searchgenetic algorithm, the results are as follows:

Taking the results of solving the model into account, the decision-making process of the retailer aimed for contracting for each product with the suppliers is determined for each scenario. Although by each of these scenarios taking place, the purchase amount of each product from corresponding supplier in each period is decided based on the associated scenario (Table 2).

\section{Conclusion}

Decision making regarding collaboration with proper supplier and the optimum quantity are vital issues among the supply chain management problems and this decision gains a more important attention in uncertain environments.

Table 2 Value of the variables of the numerical example

\begin{tabular}{llllllllll}
\hline & \multicolumn{1}{c}{$S_{1}$} & $S_{2}$ & $S_{3}$ & & $S_{1}$ & $S_{2}$ & $S_{3}$ \\
\hline$F_{111}$ & 1 & $Q_{111}$ & 1318 & & & $K_{11}$ & 0.276 & 0.000008 & 0 \\
$F_{121}$ & 1 & $Q_{121}$ & & 1680 & 960 & $K_{21}$ & 0.163 & 0.000004 & 0 \\
$F_{131}$ & 0 & $Q_{131}$ & & & & $K_{21}$ & 0.238 & 0.000005 & 0 \\
$F_{211}$ & 1 & $Q_{211}$ & & & 1350 & $K_{22}$ & 0.177 & 0.00001 & 0 \\
$F_{221}$ & 1 & $Q_{221}$ & 964 & & & Objective & 17019.11 & \\
$F_{231}$ & 1 & $Q_{231}$ & & 675 & & & & & \\
$F_{112}$ & 1 & $Q_{112}$ & 1038 & 1200 & & & & & \\
$F_{122}$ & 1 & $Q_{122}$ & & & 792 & & & & \\
$F_{132}$ & 0 & $Q_{132}$ & & & & & & & \\
$F_{212}$ & 1 & $Q_{212}$ & & 292 & 1710 & & & & \\
$F_{222}$ & 0 & $Q_{222}$ & & & & & & & \\
$F_{232}$ & 1 & $Q_{232}$ & 1456 & 608 & & & & & \\
\hline
\end{tabular}

In this article, an EOQ model for deteriorating items is developed while considering the selection of optimum suppliers. In this study, retailer determines a quantity for each of items that are vulnerable to deterioration, the suppliers from whom the items are purchased and the exact amount of the items to buy. The objective function includes ordering cost, purchase, maintenance, transportation, and shortage cost. This framework is structured through a mathematical framework and robust optimization is employed for manipulating the uncertainty, embedded in the nature of the problem. To unearth the profitable order, pattern search has been implemented to solve the model. There are some aspects that may be taken into consideration for future efforts, including studying the effect of inflation rate on results or considering prices as decision variables, to name but to.

Open Access This article is distributed under the terms of the Creative Commons Attribution 4.0 International License (http://creative commons.org/licenses/by/4.0/), which permits unrestricted use, distribution, and reproduction in any medium, provided you give appropriate credit to the original author(s) and the source, provide a link to the Creative Commons license, and indicate if changes were made.

\section{References}

Bakker M, Riezebos J, Teunter RH (2012) Review of inventory systems with deterioration since 2001. Eur J Oper Res 221(2):275-284

Bevilacqua M, Petroni A (2002) From traditional purchasing to supplier management: a fuzzy logic-based approach to supplier selection. Int J Logist 5(3):235-255

Diabat A, Taleizadeh AA, Lashgari M (2017) A lot sizing model with partial downstream delayed payment, partial upstream advance payment, and partial backordering for deteriorating items. J Manuf Syst 45(1):322-342

Ebrahim RM, Razmi J, Haleh H (2009) Scatter search algorithm for supplier selection and order lot sizing under multiple price discount environment. Adv Eng Softw 40(9):766-776

Hung K-C (2011) An inventory model with generalized type demand, deterioration and backorder rates. Eur J Oper Res 208(3):239-242

Khanlarzade N, Yegane B et al (2014) Inventory control with deteriorating items: a state-of-the-art literature review. Int J Ind Eng Comput 5(2):179-198

Kumar M, Vrat P, Shankar R (2004) A fuzzy goal programming approach for vendor selection problem in a supply chain. Comput Ind Eng 46(1):69-85

Lashgari M, Taleizadeh AA, Sana SS (2016) An inventory control problem for deteriorating items with back-ordering and financial considerations under two levels of trade credit linked to order quantity. J Ind Manag Optim 12(3):1091-1119

Lee AHI, Kang H-Y, Lai C-M, Hong W-Y (2013) An integrated model for lot sizing with supplier selection and quantity discounts. Appl Math Model 37(7):4733-4746

Li R, Lan H, Mawhinney JR (2010) A review on deteriorating inventory study. J Serv Sci Manag 3(01):117

Mulvey JM, Vanderbei RJ, Zenios SA (1995) Robust optimization of large-scale systems. Oper Res 43(2):264-281 
Rabbani A (2011) Using fuzzy logic to multi-product lot sizing problem with constraint capacity in MRP system. J Ind Manag 5:15-27

Rezaei J, Davoodi M (2011) Multi-objective models for lot-sizing with supplier selection. Int J Prod Econ 130(1):77-86

Saaty TL (2004) Decision making - the analytic hierarchy and network processes (AHP/ANP). J Syst Sci Syst Eng 13(1):1-35

Sarkar T, Ghosh SK, Chaudhuri KS (2012) An optimal inventory replenishment policy for a deteriorating item with time-quadratic demand and time-dependent partial backlogging with shortages in all cycles. Appl Math Comput 218(18):9147-9155

Senyigit E, Soylemez I (2012) The analysis of heuristics for lot sizing with supplier selection problem. Proc Soc Behav Sci 62:672-676

Skouri K, Papachristos S (2002) A continuous review inventory model, with deteriorating items, time-varying demand, linear replenishment cost, partially time-varying backlogging. Appl Math Model 26(5):603-617

Taleizadeh AA (2014) An EOQ model with partial backordering and advance payments for an evaporating item. Int J Prod Econ 155:185-193

Taleizadeh AA, Nematollahi M (2014) An inventory control problem for deteriorating items with back-ordering and financial considerations. Appl Math Model 38(1):93-109

Taleizadeh AA, Niaki STA, Aryanezhad M-B (2009a) A hybrid method of Pareto, TOPSIS and genetic algorithm to optimize multi-product multi-constraint inventory control systems with random fuzzy replenishments. Math Comput Model 49(5):1044-1057

Taleizadeh AA, Niaki STA, Hoseini V (2009b) Optimizing the multiproduct, multi-constraint, bi-objective newsboy problem with discount by a hybrid method of goal programming and genetic algorithm. Eng Optim 41(5):437-457

Taleizadeh AA, Wee H-M, Sadjadi SJ (2010a) Multi-product production quantity model with repair failure and partial backordering. Comput Ind Eng 59(1):45-54
Taleizadeh AA, Niaki STA et al (2010b) Optimising multi-product multi-chance-constraint inventory control system with stochastic period lengths and total discount under fuzzy purchasing price and holding costs. Int J Syst Sci 41(10):1187-1200

Taleizadeh AA, Niaki STA, Barzinpour F (2011) Multiple-buyer multiple-vendor multi-product multi-constraint supply chain problem with stochastic demand and variable lead-time: a harmony search algorithm. Appl Math Comput 217(22):9234-9253

Taleizadeh AA, Jalali-Naini SG, Wee H-M, Kuo T-C (2013a) An imperfect multi-product production system with rework. Sci Iran 20(3):811-823

Taleizadeh AA, Wee H-M, Jolai F (2013b) Revisiting a fuzzy rough economic order quantity model for deteriorating items considering quantity discount and prepayment. Math Comput Model 57(5):1466-1479

Taleizadeh AA, Mohammadi B, Cárdenas-Barrón LE, Samimi H (2013c) An EOQ model for perishable product with special sale and shortage. Int J Prod Econ 145(1):318-338

Taleizadeh AA, Noori-daryan M, Cárdenas-Barrón LE (2015) Joint optimization of price, replenishment frequency, replenishment cycle and production rate in vendor managed inventory system with deteriorating items. Int J Prod Econ 159:285-295

Valliathal M, Uthayakumar R (2009) An EOQ model for perishable items under stock and time-dependent selling rate with shortages. ARPN J Eng Appl Sci 4(8):8-14

Wagner HM (1975) Principles of operations research, 2nd edn. Prentice Hall, New Jersey

Xia W, Wu Z (2007) Supplier selection with multiple criteria in volume discount environments. Omega 35(5):494-504

Yu C-S, Li H-L (2000) A robust optimization model for stochastic logistic problems. Int J Prod Econ 64(1):385-397

Zhang J et al (2015) Optimal dynamic pricing and replenishment cycle for non-instantaneous deterioration items with inventorylevel-dependent demand. Int J Prod Econ 170:136-145 